\title{
Should conservation biologists push policies?
}

\section{SAN JOSE}

For conservation biologists, it's the question that wor'tgo away. Should they make the leap fromdescribing the facts of a case, to telling people what ought to be done?

Biologist ReedNoss of the

University of Central Florida believes they should. Addressing a meeting of the Society for Conservation Biology (SCB) in San Jose, Califomia, last week, he tried to convince the crowd that they have a responsibility to be notjust scientists dealing in objective facts, but also advocates pushing particularpolicies.

ButMike Scott of the University of Idaho, organizer of the symposium, thinks the SCB should stick to the facts. "We need to position ourselves as the go-to authority on conservationmatters worldwide," he says. "We can more forcefully do that if we do rigorous science, and then leave it for the decision-makers to figure out what to do with that."

The advocacy question is perhaps more difficult for conservation biologists thanmany other scientists. Their fieldis already premisedon the value of having lots of species around. And most of these scientists got into the field because of their strong feelings about nature, the wilderness and often particular species.

Peter Brussard, a population biologistat the University of Nevada, Reno, points out that the debate goes back to at least 1951. Then the Nature Conservancy split from the Ecological Society of America because of a dispute over whether scientists shoulddo more than just describe.

These days, he thinks, "the debate has been reframed a little bit", with more researchers willing to be advocates. In the end, he says, much depends on the definition of advocacy. "We never seem to get beyondsemantics."

For example, does advocacy include sending a paper to policymakers? Or to the press? Or reiteratingyour findings if you don't think policy-maker shave taken enough notice of them?

Back in San Jose, the US Geological Survey's Susan Haseltine warns the meeting of the harm a scientist can do to their credibility by being an activist. "Idon't believe you can be strong in science and in advocacy," she says.
Meanwhile, the policy-makers to whom all this advocacy is directed have their own views about the information coming from scientists. "I don't mind policy recommendations from scientists," says Andrew Wheeler, staff director and chief council of the US Senate Committee on Ervironment and Public Works, which handles conservationlegislation. "But I take them with a grain of salt."

Despite the arguments against, it looks as if the members of the SCB are coming round to Noss's point of view. In a survey of about 300 attendees, $70 \%$ felt that the voice of the society - the journal Conservation Biology - should advocate certain policies. Emma Marris 